\title{
Exploring the Experiences of Division III Athletes Drinking Alcohol With Their Teams: A Qualitative Study
}

\author{
Debra L. Fetherman and Joan Cebrick Grossman \\ The University of Scranton
}

\begin{abstract}
Self-reported alcohol use is highest among Division III athletes, which represents the largest NCAA Division. Team- or sport-related social processes related to college athletes' alcohol misuse have primarily been investigated quantitatively among Division I and II athletes. No studies have examined the experiences of the reciprocal relationship between college athletes and their teams concerning alcohol misuse. For these reasons, the purpose of this study was to explore the essential meaning that Division III athletes use to characterize their experiences of drinking alcohol with their teams. Research questions addressed what athletes experienced when drinking with their teams and what influenced or affected these experiences. During interviews with 15 athletes, consisting of male $(n=5)$ and female $(n=10)$ athletes from eight intercollegiate sports teams, four themes emerged: acceptance, comradery, safety and protection, and a gateway to college social life. Athletes also described changes in their social identities which led to responsible changes in their alcohol use and associated behaviors. Findings indicated that the malleability of athletes' social identities can change alcohol behaviors as college athletes navigate social life throughout their college years. Applying knowledge about team interpersonal dynamics and athletes' individual self-identity development may aid practitioners, athletic administrators, and coaches as they seek to reduce athletes' alcohol misuse.
\end{abstract}

Keywords: alcohol use, college athletes, social identity, team dynamics

Alcohol misuse is problematic across U.S. college campuses (Hingson, Heeren, Zakocs, Kopstein, \& Wechsler, 2002). Approximately $60 \%$ of college students reported past-month drinking, while more than one-third of those students report drinking heavily when using alcohol (i.e., four or more drinks for females and five or more for males in one sitting) (Johnston, O'Malley, Bachman, Schulenberg, \& Miech, 2014). Researchers have established that college athletes are a group at higher risk for more frequent alcohol misuse than nonathlete peers

Fetherman and Grossman are with the Exercise Science \& Sport Dept., The University of Scranton, Scranton, PA. Address author correspondence to Debra L. Fetherman at debra.fetherman@ scranton.edu. 
(Leichliter, Meilman, Presley, \& Cashin, 1998; Martens, Dams-O'Connor, \& Beck, 2006; Nelson \& Wechsler, 2001; Turissi, Mastroleo, Mallet, Larimer, \& Kilmer, 2007; Vicary \& Karshin, 2002). Most college athletes engage in substance use, particularly alcohol (Green, Uryasz, Petr, \& Bray, 2001).

Since 1998, the National Collegiate Athletic Association (NCAA) (2016) has provided 3-year CHOICES grant funding to select university athletic programs to help reduce alcohol misuse behaviors among athletes as well as their nonathlete peers. As of 2008, approximately $12 \%$ of NCAA athletic programs had participated in the CHOICES grant program. Despite this focused effort, alcohol consumption has increased significantly over the past 12 years, from $77.3 \%$ and $77.6 \%$ to $83.1 \%$ for both female and male college athletes, respectively (Bracken, 2012). Division III (DIII) athletes have a slightly higher likelihood of alcohol consumption (85.3\%) compared to Division I (DI) (81.7\%) and Division II (DII) $(81.5 \%)$ athletes (Bracken, 2012).

Division III is the largest NCAA division, representing 445 schools and approximately 180,000 athletes, with $80 \%$ of these athletes receiving financial aid and academic scholarships (Herzberger, 2016). There is an increased likelihood of alcohol use among DIII athletes, who reported drastically higher rates of drinking across a 12-month period, but lower levels of alcohol misuse compared to DI or DII athletes (Brenner, Metz, \& Brenner, 2009; Brenner \& Swanik, 2007; Green et al., 2001). Specifically, DIII athletes report drinking more frequently but consume lower levels of alcohol when they do drink. Researchers speculate that the varying athletic demands of different divisions and/or off-season versus in-season schedules may result in dissimilar alcohol use patterns. Division III athletes also indicated higher levels of campus involvement compared to DI and DIII athletes (Brenner et al., 2009).

Those athletes involved in high-risk drinking are more likely to experience negative consequences (Doumas, Turrisi, Coll, \& Haralson, 2007; Nattiv, Puffer, $\&$ Green, 1997). Perkins (2002) categorized three types of negative consequences related to alcohol misuse: damage of self, damage to other people, and institutional costs. As a result of alcohol use or other substances, student athletes have reported either being hurt or injured at least once during the year (15.3\%) (Bracken, 2012). Thirty-eight percent of collegiate athletes identified alcohol-related unintentional injuries (ARUIs) as a serious concern (Brenner, Metz, \& Entriken, 2014). Athletic trainers also identified ARUIs among collegiate athletes as a serious health problem $(73.4 \%)$ that athletic trainers should be prepared to prevent and treat (Brenner, Metz, Entriken, \& Brenner, 2014; Howell, Barry, \& Pitney, 2015). Athletic trainers working at DI institutions had a somewhat higher likelihood of treating, evaluating, and referring athletes with ARUIs (42.2\%) than at DIII institutions (30.1\%) (Brenner, Metz, Entriken, \& Brenner, 2014).

Heavy alcohol consumption has also been shown to strongly relate to interpersonal factors associated with athletic participation (Hildebrand, Johnson, \& Bogle, 2001; Leichliter et al., 1998; Lisha \& Sussman, 2010). Athletes who perceived that their teammates got drunk in the last month were more likely to report alcohol misuse or heavy drinking (Fetherman \& Bachman, 2016; Martens, Watson, \& Beck, 2006; Williams et al., 2008). Parent, peer, and coach influences were also found to be mediators for alcohol misuse in athletes (Fetherman \& Bachman, 2016; Martens, Dams-O'Connor, Duffy-Paiement, \& Gibson, 2006; Mastroleo, Marzell, Turrisi, \& Borsari, 2012). Factors related to individual 
personality traits, such as stress, team participation, and social opportunities, have also been identified as connected to college athletes' increased risk for heavy drinking (Martens, 2012). These investigations concerning athletes' subjective norms, perceptions, attitudes, and intentions are quantitative in nature, with limited findings reported on DIII athletes (Collins, Witkiewitz, \& Larimer, 2011; Martens, Dams-O-Connor, \& Duffy-Paiement, 2006; Martens, Dams-O'Connor, DuffyPaiement, \& Gibson, 2006; Norman, Bennett, \& Lewis, 1998; Norman \& Conner, 2006; Oei \& Morawska, 2004).

The social ecological model and social norms theory have been consistently used in quantitative studies to investigate various social and psychological factors that affect alcohol misuse among college athletes (Berkowitz \& Perkins, 1986; Fetherman \& Bachman, 2016; Martens, 2012; Nelson \& Wechsler, 2001; Zhou \& Heim, 2014). Recent findings indicate that individual athletes' misconceptions surrounding team social norms and the expectations of drinking in social settings influence team members to misuse alcohol. However, these studies have not adequately explored how and why team dynamics shape individual college athletes' alcohol use behaviors. A phenomenological approach that explores "what" it means to athletes to drink alcohol with their teams can shed light on the complex dynamics of the social and psychological factors inherent in their experiences (Moustakas, 1994).

Given the large number of DIII athletes and their current increased risk of alcohol use and potential misuse, more research is warranted on this subgroup of college athletes. Therefore, the purpose of this phenomenological study was to expand the existing literature by exploring and describing the essential meaning that DIII college athletes attribute to their experiences when drinking alcohol with their teams. Two questions guided this study: (1) What have you experienced when drinking with your team? and (2) What has influenced or affected your experience of drinking with your team? The study relies on the narrative descriptions of Division III college athletes during in-depth interviews.

\section{Methods}

\section{Research Design}

This research is novel in that this work sought to more deeply understand DIII athletes' common or shared experiences of drinking alcohol with their teams. Our work focuses on describing the first-hand experiences of athletes drinking with their teammates and teasing out the ways in which social and psychological factors present themselves in and through individual experiences. Using a psychological phenomenology approach, the research sought to answer "what" is the essence of athletes' experiences of drinking alcohol with their teams. Psychological phenomenology focuses on the description of participants; as such, "bracketing" out the researcher's experience with the phenomenon is important (Moustakas, 1994). The principal investigator bracketed, or wrote down personal biases and previous knowledge about college athletes' alcohol drinking behaviors, prior to data collection. Researchers incorporated additional strategies to ensure Guba's (1981) recommendations for trustworthiness were inherent in the study design (see Table 1). In the following sections, the study's design elements that were used to establish trustworthiness are further described. 


\section{Table 1 Study Trustworthiness Criteria}

\begin{tabular}{|c|c|}
\hline Criterion & Design Elements Used \\
\hline $\begin{array}{l}\text { Credibility- } \\
\text { measure what is } \\
\text { actually intended }\end{array}$ & $\begin{array}{l}\text { Recruited a range of athletes through athletic department email. } \\
\text { Participants contacted primary researcher independently. } \\
\text { Ensured confidentiality/honesty of participants' responses through } \\
\text { use of informed consent and interview script, and ability to withdraw } \\
\text { from the study at any point in process without reason. } \\
\text { Established independent status of researcher at onset of interview. } \\
\text { Primary researcher established familiarity with organization through } \\
\text { meetings and prior health promotion work. } \\
\text { Triangulation of all transcripts within the sample, and with the field } \\
\text { notes of the researcher and research assistant took place. } \\
\text { Probing, iterative questioning was used to encourage detailed } \\
\text { descriptions from participants during the interview. } \\
\text { The primary researcher revisited transcripts to ensure that themes } \\
\text { were present in each participant case. } \\
\text { Field notes were taken by both the primary researcher and research } \\
\text { assistant. } \\
\text { At the end of each interview and review of transcript, the primary } \\
\text { researcher and research assistant debriefed. } \\
\text { The co-investigator who had not participated in any interviews } \\
\text { independently analyzed the data and provided alternative data } \\
\text { interpretations or corroborated the primary researcher's interpretation. } \\
\text { The primary researcher checked the accuracy and interpretation of the } \\
\text { interview data with each participant at the conclusion of each } \\
\text { interview. } \\
\text { Participants reviewed their interview transcripts and were able to } \\
\text { make changes if needed. }\end{array}$ \\
\hline $\begin{array}{l}\text { Transferability- } \\
\text { extent to which } \\
\text { findings can be } \\
\text { applied to wider } \\
\text { population }\end{array}$ & $\begin{array}{l}\text { A thorough, clear description of the study context and participant } \\
\text { characteristics are given. } \\
\text { Limitations to the study and future recommendations are provided. }\end{array}$ \\
\hline $\begin{array}{l}\text { Dependability- } \\
\text { extent to which } \\
\text { study can be } \\
\text { repeated }\end{array}$ & $\begin{array}{l}\text { Detailed description of phenomenological research and study } \\
\text { methodology is provided. } \\
\text { Used figure to clarify data analysis method. }\end{array}$ \\
\hline $\begin{array}{l}\text { Confirmability- } \\
\text { ensure objectivity, } \\
\text { reduce bias }\end{array}$ & $\begin{array}{l}\text { Triangulation of data was used on multiple levels across participants } \\
\text { and across investigators. } \\
\text { Themes were revisited through review of transcripts. } \\
\text { Limitations of the study were recognized. } \\
\text { Used table to demonstrate study trustworthiness. }\end{array}$ \\
\hline
\end{tabular}

\section{Recruitment}

Over a 4-week period, emails were sent by the university's athletic department to all varsity athletes at a mid-Atlantic university. Participants then contacted the primary researcher via email to volunteer for the study, who then scheduled individual interviews. All participants were eligible to enter a drawing for a 
$\$ 100.00$ gift card. The study was approved by the university's institutional review board (IRB).

\section{Participants}

Participants $(n=15)$ represented a sample of Division III varsity athletes at a midAtlantic university (see Table 2). Polkinghorne (1989) recommends including at least 5 to 25 participants, while Guest, Bunce, and Johnson (2006) indicated that at least 6 interviews should be conducted for phenomenological research to ensure the depth and breadth of data. All participants self-reported drinking alcohol with their teams as well as nonathlete peers. Participants were asked to indicate if they were 18 years or older to ensure parental consent was not needed. Specific participant ages were not collected to promote honesty in self-reported alcohol use. The majority of participants were female $(67 \%)$, with the remaining $(33 \%)$ identifying as male. The sample self-identified as $87 \%$ Caucasian $(\mathrm{n}=13)$ and $13 \%$ Asian $(n=2)$. No additional participants were recruited, since no new data, themes, or coding emerged from the rich, descriptive data initially collected through the use of probing interview questions (Bowen, 2008; O'Reilly \& Parker, 2013).

Eight out of $18(44 \%)$ of the university's intercollegiate teams were represented, which included five team and three individual sports. The sample included fall, winter, and spring sport seasons. All four college years were represented in the sample, including 4 freshmen (27\%), 3 sophomores (20\%), 5 juniors (33\%), and 3 seniors (20\%). However, no male freshmen athletes participated. Twenty-seven percent of the sample consisted of team captains (one male and three female). Specific sport affiliation is not given to protect confidentiality.

\section{Table 2 Participant Characteristics}

\begin{tabular}{lccc}
\hline Pseudonym & Year in School & Gender & Sport Season \\
\hline Marie & Freshman & Female & Fall \\
Alicia & Junior & Female & Fall \\
Madison & Freshman & Female & Fall \\
Susan & Freshman & Female & Spring \\
Renee & Freshman & Female & Spring \\
Monica & Junior & Female & Spring \\
David & Junior & Male & Fall \\
Kylie & Junior & Female & Spring \\
James & Senior & Male & Winter \\
Allie & Senior & Female & Winter \\
Sam & Junior & Male & Spring \\
Michael & Senior & Male & Fall \\
Andrea & Sophomore & Female & Fall \\
Brian & Sophomore & Male & Fall \\
Lori & Sophomore & Female & Spring \\
\hline
\end{tabular}




\section{The Interview}

Consistent with phenomenological inquiry, data was collected during in-depth participant interviews (Moustakas, 1994). A semi-structured interview guide was developed and pilot tested with three college athletes to ensure that participants had the freedom to shape the interview based on their own understanding of the phenomenon (Patton, 2002). Interviews were conducted toward the end of the spring semester during a 7-week period in an on-campus meeting room.

The average duration of each interview was approximately $1 \mathrm{hr}$. An informed consent form, approved by the university's IRB was obtained at the outset of each interview. The primary researcher read a script that informed participants that: there were no "right" or "wrong" answers, they should share their unique experiences and thoughts, their comments were confidential, and honesty was encouraged. Two questions guided the interview: What have you experienced when drinking with your team? What has influenced or affected your experience of drinking with your team? The goal was to gradually involve participants to gain a sense of trust during the interview. Different follow-up questions and/or probes were asked based on the individual interview to encourage participants to talk freely, so issues could be more clearly understood (Patton, 2002). Before ending the interview, participants were given the opportunity to share anything about their experiences not previously discussed. Field notes were reviewed with each participant and corrections made if necessary prior to exiting the interview.

The primary researcher conducted each interview and took field notes, along with a research assistant who also operated a digital recorder. Each interview continued until no new themes emerged in the discussion. The primary researcher and research assistant compared their field notes for accuracy prior to exiting the interview. Interviews were audio recorded, downloaded to a computer, and transcribed verbatim by the research assistant into 230 single-spaced pages.

\section{Data Analyses}

The modified Van Kaam Method of Analysis was utilized (Moustakas, 1994) (see Figure 1). Each participant's verbatim transcript was read and re-read by the primary researcher. The narrative data was reduced by highlighting significant statements on each transcript (horizonalization). Significant statements were grouped by question and participant into tables for analysis and then combined into core themes of the experience by memos in the table margins. Saturation was confirmed through the triangulation of the data (Rebar, Gersch, Macnee, \& McCabe, 2011). All themes were found across participants regardless of team, year in school, gender, or ethnicity.

Components were then validated for verification, ensuring that the themes were represented in each participant's narrative data. Only components that were common among all participants were used to create a textural description (what athletes experienced when drinking alcohol with their teams) and structural description (how athletes experienced drinking alcohol with their teams). Finally, a description of the overall essence of the experience was constructed representing the participants as a whole. The following standards were met as described above to ensure study credibility: (1) bracketing, (2) saturation, (3) triangulation of data, 


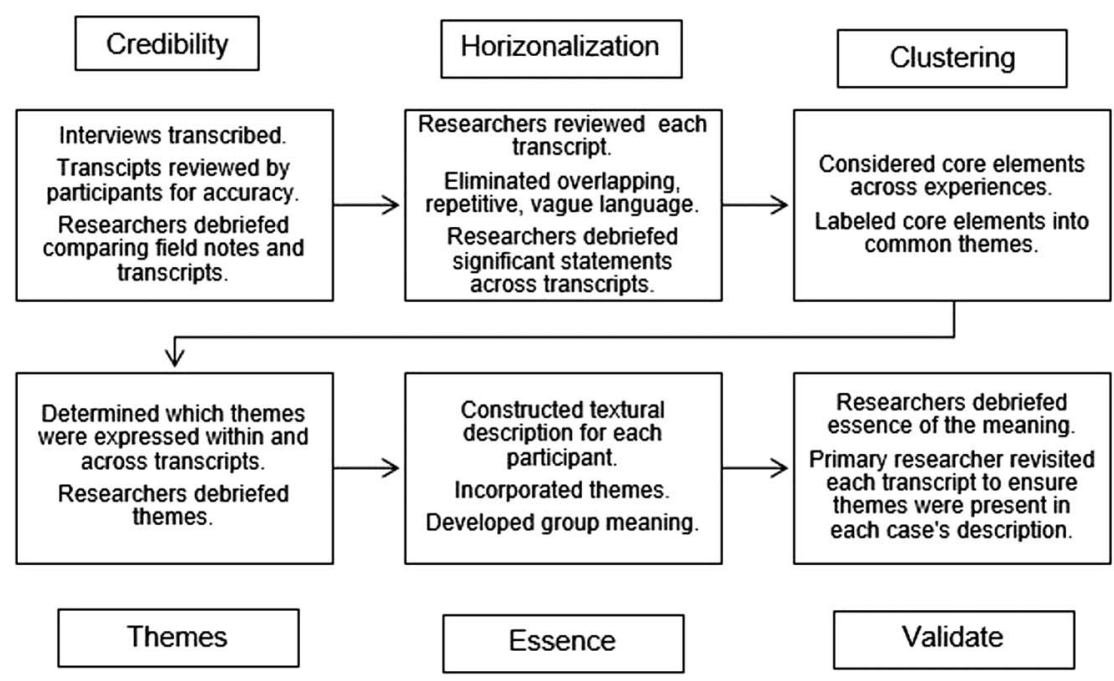

Figure 1 - Data analysis method. This figure illustrates the method used to analyze data from participants' transcripts to describe the essence of athletes' experiences.

and (4) peer debriefing among primary and secondary researchers as well as the research assistant (Creswell, 2013). Peer debriefing took place after horizonalization of the raw data by the primary researcher, clustering of data into themes, and validation of the themes by reviewing each individual participant's description.

\section{Results}

\section{Essence of Drinking Alcohol With Team}

The essential meaning that college athletes attribute to the experience of drinking alcohol with their team, is that it acts as a mechanism for navigating college social life, both as a student and an athlete. Alcohol use permeates social life in college. Drinking alcohol with the team becomes an avenue to misuse alcohol. Athletes perceive the need to drink alcohol to be accepted by their teammates. Athletes feel safe and protected when drinking alcohol with their teams. Team comradery is enhanced through drinking alcohol together. Team membership acts as a gateway to a social life. The four interrelated and interdependent themes embedded in the essential meaning are: generates feelings of acceptance, builds comradery, represents safety and protection, and provides a gateway to college social life.

\section{Theme 1: Generates Feelings of Acceptance}

Previous findings indicated an association between team approval of alcohol use and the athlete's own consumption (Hummer, LaBrie, \& Lac, 2009; Olthuis, Zamboanga, \& Ham, 2011; Turrisi, Mastroleo, Mallet, Larimer, \& Kilmer, 2007). 
Findings from the current study revealed that, regardless of their year in school, all study participants reported initially drinking alcohol with their team to feel accepted. Andrea, who remembered team parties from her freshman year, stated, "My team didn't pressure me to drink. I wanted to drink more to impress them. I wanted to drink for acceptance." James recalled:

The biggest influence to drink probably is to fit in with the team. You're young and impressionable and want to fit in with everyone. You're going to be with these people for 3-4 years. You should probably want to fit in and look like a contributing member of the team.

While seeking acceptance, participants described a variety of emotions such as "nervousness", "excitement", "enjoyment", and "comfort". Sam explained how he felt his freshmen year:

I mean I was nervous but I was comfortable at the same time because I had 15 other kids who were also becoming friends with me so it's just a good way to socialize and get comfortable with all new people.

Participants commonly described a realization as they attended college that they did not have to always drink alcohol with their teams to be "accepted" and other factors such as academics or your teammate's well-being become more important. After one semester with her team, Marie noted:

I've realized this semester, you don't need to (drink), but that's also because I know everyone a little better and, like, I'm more focused on school now. So it's like, I'll take a night off - by taking it easy one night. I felt like a lot of the pressures came from just wanting to like go - even just show how much you want to drink, cause coming in and being able to, like, chug a bunch of beers, like, as a freshmen, 'oh that's so cool' kinda thing.

Now a junior team member, Kylie reflected:

I remember how I felt as a freshman so I know that I wouldn't ever want to put my freshmen in that position. So I am always the one to say, you don't have to do anything, like if you don't even want to come you don't have to come, because I know how I felt as a freshman. I was just like scared to even show up at things like this sometimes. It would be just very overwhelming and not what I'm from - cause I'm not a partier.

\section{Theme 2: Builds Comradery}

Alcohol use among college athletes has been previously identified as a way to promote team cohesion (Zamboanga \& Ham, 2008; Zhou \& Heim, 2014). Participants in this study also pointed to the use of alcohol to create comradery among their teams. Participants specifically explained that drinking alcohol with their team was an appealing way to create friendships and a sense of community. Participants alluded that drinking alcohol made socializing easier. Andrea explained, "You feel more comfortable if you would. People don't question if you don't (drink). Everyone understands. If you didn't drink, you don't feel as close 
with the team." Participants described feeling a greater sense of "trust" and "connection" when drinking with their teammates than they experienced in other team-related activities. A junior team member, Kylie, clarified the meaning of her experience:

I had fun because it was something different. It was kinda like a way to bond with the team. Because that's kinda what they did. As opposed to what I usually do on weekends. I'll stay home and stay with my family, so it was kinda like another outlet for me to go and enjoy time with like my teammates and have like a bonding time.

David, another junior, provided this example:

I mean . . . I think it's definitely a good bonding experience I guess you could say. I mean . . you're with your teammates. You're with them on the field, off the field, so I think it builds a good connection with one another. I think it's definitely a good way to build a connection with them.

Previously, researchers have found differences between male and female college athletes' alcohol use. Male athletes seemed to be at higher risk for binge drinking and drank for social reasons with their teams, while women drank to cope with their lives (Ford, 2007; Wilson, Pritchard, \& Schaffer, 2004). However, this study's female participants tended to describe comradery when drinking alcohol with their teams as "socializing", while male participants described a "game-like, competitive atmosphere". Both male and female participants noted this same difference among sexes. Susan stated, "I think males ... they're more crazy like when they consume alcohol. They're more - like just loud and obnoxious sometimes but that's like all boys, right?" James also described this difference between males and females: "There are probably more games (at male parties), less dancing - more chugging, faster drinking more focused on that aspect rather than interacting."

\section{Theme 3: Represents Safety and Protection}

In previous research, the negative outcomes of drinking alcohol may not have been perceived as negative by female athletes if athletes perceived alcohol use as a normal way of interacting with their teams (Zamboanga \& Ham, 2008; Zamboanga, Horton, Leitkowski, \& Wang, 2006). In this study, male and female participants described feeling socially and physically safe when drinking alcohol with their teams. The athletes perceived that feelings of safety or protection were a result of the team cohesiveness or actual discussions among teammates or coaches. Marie, a freshman, detailed her experiences:

Well, I usually have a lot of fun with them and it's a safe environment I feel like. I think it's comforting to know, if you want to drink, I have a place offcampus so then that reduces the risk of getting in trouble on campus a lot. And then, it's kind of like the first night I got sick, I had a group of girls even though I didn't know them that well - they were there to like comfort me or whatever - it's kind of like a team effort, so it's kind of like a family. 
I know there's been girls that don't know their limits and so we'll be like, no stop drinking; you can start in like 20 minutes, just chill out for now. So it's kind of just like, we limit each other, so I think that it's just a safer environment.

Participants also explained the responsibility they felt for the safety and protection of their teammates when drinking alcohol. This realization seemed to occur as athletes became the upperclassmen on the teams. Some of these athletes were captains of their teams. Sam, a junior, remembered:

It's tough to say. When I was a freshman and like now, I'm in the spot where the juniors were when I was a freshman. You know how they act and how they are - I know they want to be cool, so I say if you want to drink you can, if you don't want to you don't have to, just like have fun whatever or, but, I like my team. They're like my brothers so I wouldn't do anything to hurt them or harm them.

A senior, James, revealed:

There are differences in terms of when you were on the team as a freshman and now, you know, as an upperclassmen there are differences. It's more of taking care of everyone and like overseeing everything. Supervising everyone as opposed to as a freshmen, sophomores being the wild ones running around and causing all the ruckus and stuff. Because it wasn't my house and now it is my house. I care a little more about what's going on and what everyone's doing. The amount and timing of drinking hasn't really changed that much. Just the outlook on how I go about it I guess.

However, participants acknowledged the possibility of drinking too much since they felt safe to drink with their teams. Athletes seem to assume their teammates were watching out for them. Andrea noted, "I am more comfortable drinking with the team and that can be a downside because I drink more. I trust and know them."

Participants also described being influenced by their team to not drink alcohol. The athletes explained the influence was a direct result of a conversation or indirectly-felt pressure from teammates. Brian stated:

I've heard stories about some of the younger guys who will try to drink on the down low and disregard 48-hour rule. The upperclassmen will get the message out to the younger guys to fix it. The captains wouldn't hesitate to tell our coaches and to get the message across to the guys. We want to instill a team mentality for the betterment of the team.

The desire to perform well for the team was also a regulator of drinking alcohol with the team. Lori said, "It's easy to say no. I used the excuse of performing well in the sport." Susan provided another example:

Like, out-of-season, I think people (athletes) just feel like regular students and they go out every weekend if they want. During the season, they know, like, they're conscientious. I can't, I have practice the next day, cause that'll slow me down. 
An earlier study also identified an association between perceived teammate, coach, and parent approval and the alcohol use of college athletes (Olthuis et al., 2011). Interventions that focus on team social norms have been effective in correcting normative misperceptions in college athletes, however, this did not always translate to reducing alcohol misuse in athletes (Labrie, Hummer, Grant, \& Lac, 2010; Perkins \& Craig, 2006; Thombs \& Hamilton, 2002). In this study, participants described the influence that teammates as well as coaches had on reducing alcohol misuse. Regardless of year in school, participants suggested using interactive harm reduction strategies targeted at "individual teams" led by "upperclassmen" athletes. Kylie explained:

Probably, not so much the coaches because it's kinda like they're supposed to say all that stuff. If it's coming from an upperclassmen who normally are the one's pushing for that kinda thing - like the alcohol parties and stuff. If they're the ones (upperclassmen) trying to implement a behavior change with alcohol. I think that would be more effective than hearing from your coach.

Michael, a senior, pointed to the influence of other teammates to reduce alcohol misuse:

Most effective if other student-athletes lead, either seniors or captains. I think it should focus on individual teams and address safe techniques rather than aversion. Also, talking about different circumstances that could happen might help change drinking patterns.

All participants reported that coaches would use the term "be smart" when discussing drinking alcohol. Madison, a freshman, emphasized:

Coaches say, learn from your mistakes. Be smart. Go with the right people, eat, and know your limits. Coach gave a small talk during preseason doesn't condone, but knows players are young and know students in college drink.

\section{Theme 4: Provides a Gateway to College Social life}

Alcohol use is central to social life on college campuses (Wechsler, Lee, Nelson, \& Mohler-Kuo, 2002). Research has consistently found that college athletes drink alcohol more frequently at harmful amounts and experience more alcoholrelated negative consequences than their nonathlete peers (Cadigan, Littlefield, Martens, \& Sher, 2013; Martens, Dams-O'Connor, \& Beck, 2006; Leichliter et al., 1998; Nelson \& Wechsler, 2001). Similarly, current study participants described the primary role teams had in providing alcohol for them. A freshman, Marie, stated:

I think that it's easier for college athletes to get themselves involved in alcohol. I think it helps with upperclassmen. I'm not blaming it on them - but, like, the team aspect, it's another way for teams to bond. So that's seen as a group kind of activity that everyone wants to do. So then the upperclassmen will get the freshmen, and then the freshmen will hang out with the upperclassmen. It is just like a common ground that everyone kind of participants in. 
Allie, a senior, remarked:

I feel like if I wasn't part of a team as a freshman, I wouldn't (drink). I don't know I would say I wouldn't have gone out more, but I feel like I was more inclined to just because of the group of people.

Another participant emphasized that athletes expected their teams to provide alcohol and that teams were also central to campus social life. Monica said:

Actually, I think this year the freshmen are more into it because we don't have a lot of upper classmen. There's one senior, three juniors, three sophomores, and 13 freshmen. So the freshmen girls, I feel, are the ones that initiate it (drinking) and ask more about - Are we going to drink? Are we going to do this? Like, oh my gosh, are there boys? Is it going to be fun? Are we gonna hang out here? We're like, I don't know, if you guys want to.

"Pregaming" (the practice of drinking alcohol to get drunk prior to attending an event or social function where drinking alcohol will continue) with teams also prepared athletes to extend or continue drinking alcohol at other locations off campus. Sam stated:

I mean, I live with some of my teammates in my house, so I drink with them and then some of the other kids come up and drink also. Usually we just all, I guess you could say we pregame and then go out and do our thing.

All team alcohol gatherings were described as taking place at upperclassmen teammates' off-campus houses in close proximity to campus. Participants acknowledged that drinking alcohol in off-campus team houses made it possible for them to avoid some of the legal and academic consequences of drinking alcohol. These upperclassmen also played social hosts to the broader campus community. Male sports teams' houses were perceived as common locations for off-campus house parties open to all students. Marie said, "It will be a lot of sports teams' houses where a lot of kids from sports teams will live, so they'll throw parties and that happens a lot." Monica, a junior, also made a similar comparison. She said:

I think since we don't have frats or sororities, we go to sports teams' houses. I think that is what other people get excited about, going out to house parties that are sports teams. The atmosphere is so much better. Oh, the boys' soccer or baseball team is so cute, let's go there.

\section{Discussion}

The present study contributes to the literature by providing a rich description of athletes' experiences and the changes in and interplay of their motives and influences that contribute to alcohol misuse. In our study, essential to the essence of drinking alcohol with their teams were participants' reported psychosocial development. At the outset of drinking with their teams, the value of being "accepted" was central to alcohol consumption, as participants perceived alcohol misuse as a team norm. Social norms theory has been a consistent lens through 
which athletes' behaviors and alcohol consumption have been explored (Hummer et al., 2009; Thombs, 2000; Turrisi et al., 2007). Similarly, Thombs (2000) found athletes tended to perceive higher alcohol consumption in their teammates. Additionally, higher perceptions of peer drinking have also been found to be related to reported alcohol misuse in athletes (Fetherman \& Bachman, 2016; Hummer et al., 2009; Turrisi et al., 2007). Scholars have also found that more than any other group, athletes' misperception of "drinking norms" has the greatest influence on their alcohol consumption (Dams-O'Connor, Martin, \& Martens, 2007; Lewis \& Paldino, 2008; Martens, Dams-O’Connor, \& Duffy-Paiement, 2006; Olthuis et al., 2011).

Secondarily, participants identified social motives for drinking alcohol with their teams to build comradery. Social motives for alcohol misuse among college athletes as well as nonathlete peers permeate the literature; in particular, team cohesion is central to alcohol use among athletes (Zamboanga \& Ham, 2008; Zhou \& Heim, 2014). Social motives in terms of team influence seem to be the strongest predictor of the amount of alcohol consumed, as compared to conformity or coping motives (Martens, Cox, Beck, \& Heppner, 2003). Scholars later identified three factors that best represented athletes' alcohol consumption: positive reinforcement, team/group, and sport-related coping (Martens, Watson, Royland, \& Beck, 2005).

Study participants also described that, as they attended college, a transition or change occurred in their perception that alcohol misuse was a way to be "accepted" by their team. Participants reported choosing other factors such as academics or their teammate's well-being instead of drinking alcohol with their team. From participants' descriptions, this change in belief may be interpreted as a change in the perception of team alcohol drinking norms and/or in order to do well academically_being a student was a part of their social identity as well.

Participants also reported that consuming alcohol made socializing easier with teammates. Another possibility for this change may be that the reported team comradery which developed through drinking alcohol together brought a concern for team well-being to the forefront. Similar to our study, drinking was also seen by athletes as a way to encourage team cohesion or social interaction (O'Brien, Kypri, Ali, \& Hunter, 2008; Zhou, O'Brien, \& Heim, 2014).

Participants seemed to identify with their teammates, which led to a sense of social support or friendship. Participants also explained how drinking alcohol with their teammates resulted in feeling safe and protected, and provided them with a sense of responsibility for one another. Other scholars also referred to the sense of responsibility teammates felt toward each other as a factor which may help reduce the negative consequences of alcohol use among athletes (Grossbard, Hummer, LaBrie, Pederson, \& Neighbors, 2009). However, one study participant also described that feeling "safe" with teammates may promote alcohol misuse. Identification with their teams also seemed to influence the current study participants to drink alcohol moderately or not at all, either to improve sport performance, abide by team alcohol use policies, or to "be smart". Sport or team differences have also been noted in the literature (Martens, Watson, \& Beck, 2006; Brenner \& Swanik, 2007). Sport-type differences were partially mediated by the social motives of athletes to drink with their teams (Martens, Watson, \& Beck, 2006). In our study, athletes self-reported that the social support of their teammates and their own willingness to support team goals influenced their alcohol intake. 
Other research has also documented the influence coaches and seasonal status have on changing the amount of alcohol athletes consumed (Brenner \& Swanik, 2007; Doumas et al., 2007; Hummer et al., 2009; O'Brien et al., 2008, Thombs, 2000; Turrisi et al., 2007). As previously discussed, study participants also chose to drink alcohol with their team and to meet academic responsibilities. Participants seemed to identify with both being a team member and a student. Herzberger (2016) highlighted that $80 \%$ of DIII athletes receive financial aid and academic scholarships. Thus, in this sample of athletes, student identity was also instrumental in alcohol-use behaviors.

Scholars have begun to demonstrate how individuals can use a variety of identities to make decisions about healthy behaviors (Haslam, Jetten, Postmes, \& Haslam, 2009; Oyserman, Fryberg, \& Yoder, 2012). Identity-based motivation (IBM) theory seeks to explain how self-concept, including social identities, function to influence judgment, decision making, and behaviors (Oyserman, 2007). Tarrant and Butler (2011) found that college students planned for a reduction of alcohol in consumption when their British identity was more accessible at the moment of judgment than their student identity (Tarrant \& Butler, 2011). Using an IBM perspective may be a valuable avenue to explore the phenomenon of athletes drinking alcohol with their teams. In our study, it seemed that team and student identities were malleable as participants described their experiences.

Participants also described another connection between their team and student identities. Pregaming in off-campus team houses provided initial access to drinking alcohol which continued at other off-campus locations with nonathlete peers. Previous scholars reason that college athletes have an increase in social motives compared to student peers, as athletes have a greater number of social opportunities through their teammates (Tricker, Cook, \& McGuire, 1989). Participants also expected upperclassmen teammates to act as social hosts to teammates and the broader college campus. Teammates were also seen as being able to reduce alcohol misuse among athletes through leading team-based harm reduction interventions. In support, Dams-O'Connor et al. (2007) found that social-norms-based alcohol misuse interventions targeted at athletes were more effective when led by teammates.

\section{Limitations}

This study was not without limitations. This study explored the sensitive concern of alcohol misuse in college athletes and, as such, the participants' responses may not have been completely honest or accurate. Secondly, participants only represented one of the approximately 1,000 NCAA DIII athletic programs. Additionally, not all sports were represented in this sample. Thus, caution should be taken to generalize results to all NCAA athletes.

Future research on alcohol misuse in college athletes should begin to address the generalizability of this study's findings. Comparing the differences in alcohol misuse among athletes from multiple samples of NCAA DIII schools would be helpful. Malterud, Siersma, and Guassora (2016) recommend applying the concept of "information power" to ensure data "saturation" in qualitative interview research. Thus, the adequateness of the sample or "saturation" could be 
strengthened by including: (1) equal numbers of male and female participants, (2) participants representative of every NCAA DIII sport, and (3) a longitudinal methodology which involved interviewing athletes each year over the 4 years of their collegiate athletic participation. Athletes would then provide "real-time" accounts of their experiences as opposed to recalling their lived experiences from earlier years. Holland (2007) identifies a longitudinal qualitative research model where participants are followed up with after a period of time.

Prior researchers have found intercollegiate sport-type and gender differences in the prevalence of reported alcohol use and misuse (Martens, Watson, \& Beck, 2006; Bracken, 2012). There were also no male freshman participants, and the majority of participants $(67 \%)$ were female $(n=10)$ and Caucasian $(87 \%, n=13)$. Martens, Watson, and Beck (2006) reported a difference in drinking habits based on specific sport and gender; in the study, males generally drank more than females, while male swimming/diving, soccer, and baseball athletes reported higher alcohol misuse than other sports such as basketball and track and field. Brenner and Swanik (2007) also found that athletes participating in team sports reported higher rates of alcohol misuse (84\%) compared to individual sport athletes (57\%). Nonetheless, all themes commonly emerged across participants regardless of team, year in school, gender, or ethnicity. Despite these limitations, to our knowledge, there are no other qualitative studies that investigate the meaning athletes attribute to drinking alcohol with their teams.

\section{Conclusion and Implications for Practice}

Our study supports the prior interrelated motives identified by other scholars to explain or predict alcohol misuse among college athletes. The acceptance and comradery that study athletes experienced provided social support as athletes navigated college social life. The safety and protection athletes felt from teammates influenced alcohol misuse. However, this study is novel in that it highlights the psychosocial development athletes experience when drinking alcohol with their teams. The ability to capitalize on these transitions in athletes' perceptions may be helpful in decreasing alcohol misuse among college athletes. Our study also indicates that the malleability of athletes' social identities (team identity, student identity) can change alcohol behaviors. Differences in reported alcohol misuse have been reported as college students transition into and out of intercollegiate athletic involvement (Cadigan et al., 2013). Additionally, an athlete's ability to identify with teammates makes athletes ideal candidates for leading alcohol education interventions targeted at teams.

Our findings provide new insights into the experiences of college athletes drinking alcohol with their teams. Drinking experiences with teammates help shape the psychosocial development of athletes. These insights give practitioners, athletic administrators, and coaches new knowledge that can inform and guide the development of effective alcohol education interventions to reduce athletes' alcohol misuse. Since developing psychosocially is essential throughout the lifespan, and alcohol misuse is a common part of social life, we suggest that alcohol interventions target athletes' psychosocial development and team interpersonal dynamics. For example, interventions which bring together athletes by 
year in college to discuss alternative ways to generate acceptance on teams and build comradery off the field may be beneficial. Also, upperclassman athletes' role playing and sharing their feelings, misperceptions, and experiences as a new team member would help reduce the stress younger teammates may experience as new members of the team.

Athletes also identified as being both an athlete and a student. Interventions targeted at athletes could discuss the influence of both social identities on athletes' alcohol drinking behaviors. Interventions just based on social norms theory have had mixed results (Perkins \& Craig, 2006; Thombs \& Hamilton, 2002). Team membership provides a gateway to alcohol use, creating a susceptibility for social hosting violations. Social hosting education should be considered as part of a comprehensive prevention strategy and policy. Another important implication for practice is the acknowledgment of psychosocial development as an individual experience. Creating interventions which integrate social norms theory with identity development theory would be beneficial. With this in mind, individual feedback and guidance on alcohol use is warranted. A majority of athletes desire additional education on alcohol use than they are currently receiving (Brenner \& Swanik, 2007). University counseling offices can provide individual screening and alcohol education in a group setting to assist athletic programs. Further qualitative research exploring the impact that psychosocial identity development, the role of social identities, and team interpersonal dynamics play on athletes' alcohol misuse is needed.

\section{References}

Berkowitz, A.D., \& Perkins, H.W. (1986). Resident advisors as role models: A comparison of drinking patterns of resident advisors and their peers. Journal of College Student Personnel, 27(2), 146-153.

Bowen, G. (2008). Naturalistic inquiry and the saturation concept: A research note. Qualitative Research, 8(1), 137-152. doi:10.1177/1468794107085301

Bracken, N.M. (2012). National study of substance use trends among NCAA college student-athletes. Indianapolis, IN: National Collegiate Athletic Association.

Brenner, J.W., Metz, S.M., \& Brenner, C.J. (2009). Campus involvement, perceived campus connection, and alcohol use in college athletes. Journal of Drug Education, 39(3), 303-320. PubMed ID: 20196334 doi:10.2190/DE.39.3.f

Brenner, J.W., Metz, S.M., \& Entriken, J. (2014). Alcohol-related unintentional injury among collegiate athletes. Athletic Training \& Sports Health Care, 6(5), 228-236. doi:10.3928/19425864-20140916-04

Brenner, J.W., Metz, S.M., Entriken, J., \& Brenner, C.J. (2014). Experiences and attitudes of collegiate athletic trainers regarding alcohol-related unintentional injury in athletes. Journal of Athletic Training, 49(1), 83-88. PubMed ID: 24377956 doi:10.4085/10626050-48.6.02

Brenner, J., \& Swanik, K. (2007). High-risk drinking characteristics in collegiate athletes. Journal of American College Health, 56(3), 267-272. PubMed ID: 18089508 doi:10. 3200/JACH.56.3.267-272

Cadigan, J.M., Littlefield, A.K., Martens, M.P., \& Sher, K.J. (2013). Transitions into and out of intercollegiate athletic involvement and risky drinking. Journal of Studies on Alcohol and Drugs, 74(1), 21-29. PubMed ID: 23200147 doi:10.15288/jsad.2013. 74.21 
Collins, S.E., Witkiewitz, K., \& Larimer, M.E. (2011). The theory of planned behavior as a predictor of growth in risky college drinking. Journal of Studies on Alcohol and Drugs, 72(2), 322-332. PubMed ID: 21388605 doi:10.15288/jsad.2011. 72.322

Creswell, J.W. (2013). Qualitative inquiry and research design: Choosing among five approaches. (3rd ed.). Thousand Oaks, CA: Sage Publications, Inc.

Dams-O'Connor, K., Martin, J.L., \& Martens, M.P. (2007). Social norms and alcohol consumption among intercollegiate athletes: The role of athlete and nonathlete reference groups. Additive Behaviors, 32(11), 2657-2666. PubMed ID: 17544589 doi:10. 1016/j.addbeh.2007.04.030

Doumas, D.M., Turrisi, R., Coll, K.M., \& Haralson, K. (2007). High-risk drinking in college athletes and nonathletes across the academic year. Journal of College Counseling, 10(2), 163-174. doi:10.1002/j.2161-1882.2007.tb00016.x

Fetherman, D.L., \& Bachman, J.L. (2016). Social ecological examination of alcohol use among division III athletes. American Journal of Health Studies, 31(2), 82-91.

Ford, J.A. (2007). Substance use among college athletes: A comparison based on sport/team affiliation. Journal of American College Health, 55(6), 367-373. PubMed ID: 17517549 doi:10.3200/JACH.55.6.367-373

Green, G.A., Uryasz, F.D., Petr, T.A., \& Bray, C.D. (2001). NCAA study of substance use and abuse habits of college student-athletes. Clinical Journal of Sport Medicine, 11(1), 51-56. PubMed ID: 11176146 doi:10.1097/00042752-200101000-00009

Grossbard, J., Hummer, J., LaBrie, J., Pederson, E., \& Neighbors, C. (2009). Is substance use a team sport? Attraction to team, perceived norms, and alcohol and marijuana use among male and female intercollegiate athletes. Journal of Applied Sport Psychology, 21(3), 247-261. doi:10.1080/10413200903019145

Guba, E.G. (1981). Criteria for assessing the trustworthiness of naturalistic inquiries. Educational Communication and Technology Journal, 29(2), 75-91.

Guest, B., Bunce, A., \& Johnson, L. (2006). How many interviews are enough? An experiment with data saturation and variability. Field Methods, 18(1), 59-82. doi:10. 1177/1525822X05279903

Haslam, S.A., Jetten, J., Postmes, T., \& Haslam, C. (2009). Social identity, health and wellbeing: An emerging agenda for applied psychology. Applied Psychology, 58(1), 1-23. doi:10.1111/j.1464-0597.2008.00379.x

Herzberger, S. (2016). The division III experience. Retrieved from http://www.ncaa.org/ division-iii-experience

Hildebrand, K.M., Johnson, D.J., \& Bogle, K. (2001). Comparison of patterns of alcohol use between high school and college athletes and nonathletes. College Student Journal, 35(3), 358-365.

Hingson, R.W., Heeren, T., Zakocs, R.C., Kopstein, A., \& Wechsler, H. (2002). Magnitude of alcohol-related mortality and morbidity among U.S. college students ages 18-24. Journal of Studies on Alcohol, 63(2), 136-144. PubMed ID: 12033690 doi:10.15288/ jsa.2002.63.136

Holland, J. (2007). Qualitative longitudinal research: Exploring ways of researching lives through time. Real life methods node of the ESRC national centre for research methods workshop held at London South Bank University 2007 [PDF file], 1-15. Retrieved from http://citeseerx.ist.psu.edu/viewdoc/download?doi=10.1.1.485.7802\& rep=rep $1 \&$ type $=$ pdf

Howell, S.M., Barry, A.E., \& Pitney, W.A. (2015). Exploring the athletic trainer's role in assisting student-athletes presenting with alcohol-related unintentional injuries. Journal of Athletic Training, 50(9), 977-980. PubMed ID: 26287493 doi:10.4085/ 1062-6050-50.5.09 
Hummer, J.F., LaBrie, J.W., \& Lac, A. (2009). The prognostic power of normative influences among NCAA student-athletes. Addictive Behavior, 34(6-7), 573-580. PubMed ID: 19406582 doi:10.1016/j.addbeh.2009.03.021

Johnston, L.D., O’Malley, P.M., Bachman, J.G., Schulenberg, J.E., \& Miech, R.A. (2014). Monitoring the Future national survey results on drug use, 1975-2013: Volume 2, College students and adults ages 19-55. Ann Arbor, MI: Institute for Social Research, The University of Michigan. Retrieved from http://www.monitoringthefuture.org/ pubs/monographs/mtf-vol2_2013.pdf

Labrie, J.W., Hummer, J.F., Grant, S., \& Lac, A. (2010). Immediate reductions in misperceived social norms among high-risk college student groups. Addictive Behaviors, 35(12), 1094-1101. PubMed ID: 20817409 doi:10.1016/j.addbeh.2010.08.003

Leichliter, J.S., Meilman, P.W., Presley, C.A., \& Cashin, J.R. (1998). Alcohol use and related consequences among students with varying levels of involvement in college athletics. Journal of American College Health, 46(6), 257-262. PubMed ID: 9609972 doi:10.1080/07448489809596001

Lewis, T.F., \& Paldino, D.A. (2008). Proximal norms, selected sociodemographics, and drinking behavior among university student athletes. Journal of Addictions and Offender Counseling, 29(1), 7-21. doi:10.1002/j.2161-1874.2008.tb00040.x

Lisha, N.E., \& Sussman, S. (2010). Relationship of high school and college sports participation with alcohol, tobacco, and illicit drug use: A review. Addictive Behaviors, 35(5), 399-407. PubMed ID: 20100638 doi:10.1016/j.addbeh.2009.12.032

Malterud, K., Siersma, V.D., \& Guassora, A.D. (2016). Sample size in qualitative interview studies: Guided by information power. Qualitative Health Research, 26(13), 1753-1760. PubMed ID: 26613970 doi:10.1177/1049732315617444

Martens, M.P. (2012). Alcohol interventions for college student-athletes. In H.R. White \& D.L. Rabiner (Eds.), College drinking and drug use (pp. 203-220). New York, NY: Guilford Press.

Martens, M.P., Cox, R.H., Beck, N.C., \& Heppner, P.P. (2003). Measuring motivations for intercollegiate athlete alcohol use: A conformity factor analysis of the drinking motives measure. Psychological Assessment, 15(2), 235-239. PubMed ID: 12847784 doi: 10.1037/1040-3590.15.2.235

Martens, M.P., Dams-O'Connor, K., \& Beck, N.C. (2006). A systematic review of college student-athlete drinking: Prevalence rates, sport-related factors and interventions. Journal of Substance Abuse Treatment, 31(3), 305-316. PubMed ID: 16996393 doi:10.1016/j.jsat.2006.05.004

Martens, M.P., Dams-O'Connor, K., \& Duffy-Paiement, C. (2006). Comparing off-season with in-season alcohol consumption among intercollegiate athletes. Journal of Sport and Exercise Psychology, 28(4), 502-510. doi:10.1123/jsep.28.4.502

Martens, M.P., Dams-O'Connor, K., Duffy-Paiement, C., \& Gibson, J.T. (2006). Perceived alcohol use among friends and alcohol consumption among college athletes. Psychology of Addictive Behaviors, 20(2), 178-184. PubMed ID: 16784364 doi:10.1037/ 0893-164X.20.2.178

Martens, M.P., Watson, J.C., \& Beck, N.C. (2006). Sport-type differences in alcohol use among intercollegiate athletes. Journal of Applied Sport Psychology, 18(2), 136-150, doi:10.1080/10413200600653758

Martens, M.P., Watson, J.C., Royland, E.M., \& Beck, N.C. (2005). Development of the athlete drinking scale. Psychology of Addictive Behaviors, 19(2), 158-164. PubMed ID: 16011386 doi:10.1037/0893-164X.19.2.158

Mastroleo, N.R., Marzell, M., Turrisi, R., \& Borsari, B. (2012). Do coaches make a difference off the field? The examination of athletic coach influence on early college student drinking. Addiction Research \& Theory, 20(1), 64-71. PubMed ID: 24639626 doi:10.3109/16066359.2011.562621 
Moustakas, C. (1994). Phenomenological research methods. Thousand Oaks, CA: Sage.

National Collegiate Athletic Association. (2016). Best of choices: Alcohol education 1998-2008. Retrieved from http://www.ncaa.org/sites/default/files/BestofChoices 2009.pdfgrants

Nattive, A., Puffer, J.C., \& Green, G.A. (1997). Lifestyles and health risk of collegiate athletes: A multi-center study. Clinical Journal of Sports Medicine, 7(4), 262-272. PubMed ID: 9397325 doi:10.1097/00042752-199710000-00004

Nelson, T.F., \& Wechsler, H. (2001). Alcohol and college athletes. Medicine \& Science in Sports \& Exercise, 33(1), 43-47. PubMed ID: 11194110 doi:10.1097/00005768200101000-00008

Norman, P., Bennett, P., \& Lewis, H. (1998). Understanding binge drinking among young people: An application of the theory of planned behaviour. Health Education Research, 13(2), 163-169. PubMed ID: 10181015 doi:10.1093/her/13.2.163-a

Norman, P., \& Conner, M. (2006). The theory of planned behaviour and binge drinking: Assessing the moderating role of past behaviour within the theory of planned behavior. British Journal of Health Psychology, 11(Pt 1), 55-70. PubMed ID: 16480555 doi: 10.1348/135910705X43741

O’Brien, K.S., Kypri, K., Ali, A., \& Hunter, J.A. (2008). Gender equality in university sportspeople's drinking. Drug and Alcohol Review, 27(6), 659-665. PubMed ID: 19378448 doi:10.1080/09595230801935664

Oei, T.P., \& Morawska, A. (2004). A cognitive model of binge drinking: The influence of alcohol expectancies and drinking refusal self-efficacy. Addictive Behavior, 29(1), 159-179. PubMed ID: 14667427 doi:10.1016/S0306-4603(03)00076-5

O'Reilly, M., \& Parker, N. (2013, April). Unsatisfactory saturation: A critical exploration of the notion of saturated sample sizes in qualitative research. Qualitative Research Journal, 13(2):190-197. doi:10.1177/1468794112446106

Olthuis, J.V., Zamboanga, B.L., \& Ham, L.S. (2011). Social influences, alcohol expectancies, and hazardous alcohol use among college athletes. Journal of Clinical Sport Psychology, 5(1), 24-43. doi:10.1123/jcsp.5.1.24

Oyserman, D. (2007). Social identity and self-regulation. In A.W. Kruglanski \& E.T. Higgins (Eds.), Social psychology: Handbook of basic principles (pp. 432-453). New York, NY: Guilford.

Oyserman, D., Fryberg, S.A., \& Yoder, N. (2012). Identify-based motivation and health. Journal of Personality and Social Psychology, 93(6), 1011-1027. PubMed ID: 18072851 doi:10.1037/0022-3514.93.6.1011

Patton, M.Q. (2002). Qualitative research and evaluation methods. (3rd ed.). Thousand Oaks, CA: Sage Publications, Inc.

Perkins, H.W. (2002). Surveying the damage: A review of research on consequences of alcohol misuse in the college population. Journal of Studies in Alcohol, (14), 91-100. PubMed ID: 12022733 doi:10.15288/jsas.2002.s14.91

Perkins, H.W., \& Craig, D.W. (2006). A successful social norms campaign to reduce alcohol misuse among college student-athletes. Journal of Studies on Alcohol, 67(6), 880-889. PubMed ID: 17061005 doi:10.15288/jsa.2006.67.880

Polkinghorne, D.E. (1989). Phenomenological research methods. In R.S. Valle \& S. Halling (Eds.), Existential-phenomenological perspectives in psychology (pp. 41-60). New York, NY: Plenum.

Rebar, C.R., Gersch, C.J., Macnee, C.L., \& McCabe, S. (2011). Understanding nursing research (3rd ed.). London UK: Lippincott Williams \& Wilkins.

Tarrant, M., \& Butler, K. (2011). Effects of self-categorization on orientation towards health. British Journal of Social Psychology, 50(Pt 1), 121-139. PubMed ID: 21366615 doi:10.1348/014466610X511645 
Thombs, D.L. (2000). A test of the perceived norms model to explain drinking patterns among university student athletes. Journal of American College Health, 49(2), 75-83. PubMed ID: 11016131 doi:10.1080/07448480009596287

Thombs, D.L., \& Hamilton, M.J. (2002). Effects of a social norm feedback campaign on the drinking norms and behavior of division I student-athletes. Journal of Drug Education, 32(3), 227-244. PubMed ID: 12379053 doi:10.2190/2UYU-6X9M-RJ65-3YYH

Tricker, R., Cook, D.L., \& McGuire, R. (1989). Issues related to drug abuse in college athletics: Athletes at risk. The Sport Psychologist, 3(2), 155-165. doi:10.1123/tsp.3. 2.155

Turrisi, R., Mastroleo, N.R., Mallet, K.A., Larimer, M.E., \& Kilmer, J.R. (2007). Examination of the mediational influences of peer norms, environmental influences, and parent communications on heavy drinking in athletes and nonathletes. Psychology of Addictive Behaviors, 21(4), 453-461. PubMed ID: 18072827 doi:10.1037/0893-164X. 21.4.453

Vicary, J.R., \& Karshin, C.M. (2002). College alcohol abuse: A review of the problems, issues, and prevention approaches. The Journal of Primary Prevention, 22(3), 299-331. doi:10.1023/A:1013621821924

Wechsler, H., Lee, J.R., Nelson, T.F., \& Mohler-Kuo, M. (2002). Underage college students' drinking behavior, access to alcohol, and the influence of deterrence policies: Findings from the Harvard school of public health college alcohol study. Journal of American College Health, 50(5), 223-236. PubMed ID: 11990980 doi:10.1080/ 07448480209595714

Williams, R.D., Perko, M.A., Usdan, S.L., Leeper, J.D., Belcher, D., \& Leaver-Dunn, D.D. (2008). Influences of alcohol use among NCAA athletes: Application of the social ecology model. American Journal of Health Studies, 23(3), 151-159.

Wilson, G.S., Pritchard, M.E., \& Schaffer, J. (2004). Athletic status and drinking behavior in college students: The influence of gender and coping styles. Journal of American College Health, 52(6), 269-275. PubMed ID: 15134101 doi:10.3200/JACH.52.6. 269-275

Zamboanga, B.L., \& Ham, L.S. (2008). Alcohol expectancies and context-specific drinking behaviors among female college athletes. Behavior Therapy, 39(2), 162-170. PubMed ID: 18502249 doi:10.1016/j.beth.2007.06.002

Zamboanga, B.L., Horton, N.J., Leitkowski, L.K., \& Wang, S.C. (2006). Do good things come to those that drink? A longitudinal investigation of drinking expectancies and hazardous alcohol use in female college athletes. Journal of Adolescent Health, 39(2), 229-236. PubMed ID: 16857535 doi:10.1016/j.jadohealth.2005.11.019

Zhou, J., \& Heim, D. (2014). Sports and spirits: A systematic qualitative review of emergent theories of student-athlete drinking. Alcohol and Alcoholism, 49(6), 604-617. PubMed ID: 25249539 doi:10.1093/alcalc/agu061

Zhou, J., O'Brien, K.S., \& Heim, D. (2014). Alcohol consumption in sportspeople: The role of social cohesion, identity and happiness. International Review for the Sociology of Sport, 49(3-4), 278-293. doi:10.1177/1012690213493105 